\title{
BARRIERS TO CONSTRUCTION INDUSTRY STAKEHOLDERS' ENGAGEMENT WITH SUSTAINABILITY: TOWARD A SHARED KNOWLEDGE EXPERIENCE
}

\author{
Ian E. WILSON, Yacine REZGUI \\ School of Engineering, Cardiff University, CF24 3AA Cardiff, Wales \\ Received 06 September 2011; accepted 27 January 2012
}

\begin{abstract}
Sustainability ill-practices in the construction industry can have major drawbacks on meeting governmental targets on carbon and energy reduction. Using a mixed-method approach drawn from three studies to explore the level of engagement of construction stakeholders in adopting government sustainability agendas, the research identifies a wide range of perceived barriers, which operate broadly at 'individual' and 'organisational' levels. Sustainability knowledge in construction is fragmented, diverse, embedded in various documents, and developed in a non-concerted and integrated way across stakeholders, localities, regions, and countries. There is an emergent need for a socio-technical 'knowledge solution' to create circles of impacts that bind building professionals, energy administrations, and citizens in a shared sustainability experience to address a number of issues.
\end{abstract}

Keywords: sustainable construction, awareness, engagement, knowledge management, stakeholder perceptions, behaviour.

Reference to this paper should be made as follows: Wilson, I. E.; Rezgui, Y. 2013. Barriers to construction industry stakeholders' engagement with sustainability: toward a shared knowledge experience, Technological and Economic Development of Economy 19(2): 289-309.

JEL Classification: A12, C80, D83, L74, L86 O33, Q01.

\section{Introduction}

The UK government has raised political and economic attention on the state of the climate, in particular during its presidency of the European Union in 2005 and the G8, and has set to meet EU commitments to achieve an $80 \%$ cut in $\mathrm{CO}_{2}$ emissions by 2050 (HM Government 2010). It is widely acknowledged that our built environment is responsible for some of the most serious global and local environmental change (European Commission 2005; BERR 2007;

Corresponding author Yacine Rezgui

E-mail:RezguiY@cardiff.ac.uk 
Clarke et al. 2008). Creation and operation of the built environment accounts for at least $50 \%$ of all energy consumption in Europe (Martinaitis 2006; European Commission 2005), conversely, in the UK more than $50 \%$ of all carbon emissions can be attributed to energy use in buildings (MPA 2011). The construction industry therefore faces pressure to increase the sustainability of its practices, which is understood to imply significant changes in the industry's understanding of the demands of society and of its clients, as well as its own sense of corporate social responsibility, and implies major changes in its working practices (Rezgui 2007; Rezgui, Miles 2011).

Following a 2007 announcement for zero carbon homes from 2016, the UK Chancellor of the Exchequer announced in the 2008 budget a zero carbon target for schools from 2016, Public sector buildings from 2018, and all other non-domestic buildings from 2019 (BSRIA 2009). Supporting these policy requirements, the UK building regulations have already gone through a number of amendments with the next expected in 2013, with the target $\mathrm{CO}_{2}$ reductions embedded. Wales, which forms the focus of the research, has set aspirations for zero carbon for new buildings earlier than proposed in the rest of the UK (WAG 2009).

Whilst there is a wide public awareness of climate change acknowledging main causes and concerns (DEFRA 2002), and scientific evidence highlights the significance of the human factor in reducing the impact of climate change (IPCC 2001, 2007; Schellnhuber et al. 2006), only a minority engage with effective measures to reduce their lifestyle impacts on the environment (Norton, Leaman 2004; Lorenzoni et al. 2007). Reducing the impact of climate change is linked fundamentally to our built environment and implies a need for a radical change in values and behaviour towards a paradigm of sustainable construction. In fact, the aspiration for energy and $\mathrm{CO}_{2}$ reduction by the UK government inevitably involves the need for widespread social change, including by citizens (Lorenzoni et al. 2007).

Significant discrepancies between public awareness about climate change and natural resource depletion, on the one hand, and behavioural change, on the other, have been noted (Lorenzoni et al. 2007; Whitmarsh et al. 2011), suggesting complex interactions of psychological, social and environmental factors influencing behaviour (van Vliet et al. 2005; Whitmarsh et al. 2011).

While there is considerable work towards regulating the energy and construction sectors, there is less systematic evidence regarding stakeholder responses to whole-system transformations and how such transformations are likely to be experienced, enacted and negotiated in terms of stakeholders' everyday practice and work. Building on existing literature, this paper explores the constraints and factors that influence individual stakeholders of the construction industry to adopt sustainable practices at work, including changing their own behaviour, the reasons underlying these perceived constraints, and policy implications for encouraging engagement. The paper draws upon findings of three recent mixed-method studies conducted across Europe and in the UK (Wales) on stakeholder perceptions and responses to sustainable construction. Moreover, the research involves a critical understanding of: (a) the role that stakeholders' activities play in influencing carbon emissions and energy consumption; (b) stakeholders' sustainability information sources and how these are perceived and used. 


\section{Related works}

Related to the core theme of the paper, it is interesting to note that despite a large public awareness of climate change and a general shared concern (Spence et al. 2011), there is limited behavioural response from the general public (Lorenzoni et al. 2007). Research indicates that the socio-technical practices that impact on sustainability are embedded in the everyday; that is, they are intangible and largely taken-for-granted (Burgess, Nye 2008). As a consequence, construction industry practitioners, who predominantly work for Small and Medium-size Enterprises (SME), are unlikely to be fully aware of the daily practice implications resulting from transformations within current policy and regulatory environments (Rezgui et al. 2010).

The construction industry is characterised by a complex socio-cultural and organisational environment reflected by its endemic resistance to change (Vakola, Wilson 2004) and the requirement for different management strategies due to contradictory interests of owners, contractors and craftsmen (Lill 2009); indeed it is perceived as 'unique' when compared with other sectors (Egemen, Mahomed 2005). In developing the regulatory environment to meet carbon and energy reduction targets, it is essential to enable long-term changes in individual attitudes and behaviours while promoting positive engagement.

The term "engagement" in this paper extends a previous definition by Lorenzoni et al. (2007) which concurrently involves cognitive, affective and behavioural aspects at an individual level to embrace wider values embedded within the organisational culture. In fact, social identity is perceived to be an important influence on people's energy behaviour (Steg et al. 2001; Nye et al. 2010), which implicitly highlights the difficulty in changing consumption habits. Whitmarsh et al. (2011) discuss the convergence of findings from the work around public engagement with climate change and the work on learning about climate change and carbon, and argue that the literature demonstrates that both individual and institutional dimensions of engagement are vital to understanding barriers to adoption of low-carbon lifestyles. Furthermore, they highlight the need to understand the 'situated' meanings associated with carbon; i.e. how individuals translate and apply knowledge about carbon and climate change to their daily lives through processes of objectification and anchoring.

In direct relation to this paper, Mathur et al. (2008) explore stakeholder engagement in sustainable construction. They note three distinct approaches for conceptualizing stakeholder engagement in construction projects. These relate to viewing stakeholder engagement as: a management technique; an ethical requirement; or a forum for dialogue to facilitate mutual social learning. They argue that stakeholder engagement should be considered from the perspective of an opportunity for social learning. They suggest that dialogue can be useful in increasing awareness, changing attitudes and affecting behaviours. They offer a comprehensive review of stakeholder management and its research and practice in construction.

Hence, engagement is here seen as both an individual and collective phenomenon reflected in the team and project-based nature of the construction industry. Stern (2000) argues that in addition to attitudinal factors, behaviours are influenced by contextual forces, personal capabilities and habits. This is in line with related literature drawn from environmental psychology which highlights the influences of past behaviour, knowledge, experiences, feelings, social networks, and institutional trust on individual attitudes and behaviour towards environmental issues (Blake 2001; Kollmuss, Agyeman 2002). 
Models of these various factors have been proposed, including the theory of reasoned action (Ajzen, Sheikh 2013) and theory of planned behaviour (Ajzen 1991) which postulates that beliefs determine intention to act. However, these theories have been critiqued on the grounds that they present an individualistic and rational perspective of behaviour, and consequently more contextual models have been proposed (e.g. Marks et al. 2008). It is interesting to note Tanner's (1999) ipsative theory of behaviour which identifies internal and external conditions as potential constraints to pro-environmental action.

Whitmarsh et al. (2009) define the concept of carbon capability as: 'The ability to make informed judgments and to take effective decisions regarding the use and management of carbon, through both individual behaviour change and collective action'. Three core dimensions of carbon capability are identified (Whitmarsh et al. 2011): (a) decision-making (knowledge, skills, motivations and judgments), (b) individual behaviour or 'practices' (e.g. energy conservation), and (c) broader engagement with systems of provision and governance (e.g. lobbying, voting, protesting, creating alternative social infrastructures of provision). While this addresses larger public concerns, there is a gap in similar understanding of stakeholders across the construction value chain, which is addressed by the paper.

\section{Methodology}

A methodological challenge for the research is to avoid a narrow scoping of the research questions thereby providing a stimulus for meaningful engagement by the research participants (i.e. construction stakeholders). Evidence from behavioural decision research indicates that people do not come to unfamiliar or complex technological issues with fully formed views but nevertheless can be supported in the construction of their preferences through systematic elicitation and deliberative procedures (Morgan et al. 2002; Lichtenstein, Slovic 2006). Hence, the research utilises a mixed-method approach involving three studies incorporating qualitative and quantitative methods. The research is located within theoretical traditions that take socio-technical systems as the focal unit of analysis (Rip, Kemp 1998). This perspective provides a robust foundation for analysing whole built environment sustainability systems understood as linked processes of social and technological practices (Smith et al. 2005).

The paper addresses two research questions:

- RQ1: What are construction stakeholders' sustainability information needs and government provision deficiencies?

- RQ2: What are construction stakeholders' engagement barriers with governmental carbon and energy reduction targets?

These questions were explored via three mixed-method studies. The first study, which addressed RQ1, employed an online Europe-wide survey (February-April 2009) from which 252 responses were received with participants being demographically representative of the total population sampled. Quantitative data were analyzed in SPSS and qualitative data were coded thematically in NVivo. Limited sustainability best practice, regulation awareness and information provision deficiencies emerged as key themes from the consultation and provided the ground to address RQ2. To address this question the methodology employed two further studies focused on industry consultations in Wales. The second study was via three workshops 
(c.70 participants in total) and a series of 15 semi-structured interviews with key industry representatives (May-September 2009). The first two workshops explored stakeholders' knowledge, understanding, attitudes, values and behaviours, and helped identify key barriers to sustainability engagement in Wales which were then debated and confirmed in a third workshop hosted by the Low/Zero Carbon Hub in Wales (Wales LZC Hub). The Wales LZC Hub is a coalition that is supported by the Welsh Government, the building industry, housing, and voluntary sectors, to help meet the policy targets. The findings from these workshops fed forward to a series of interviews where identified barriers were discussed from a variety of socio-technical perspectives. The third study involved consultations within two workshops and 13 focus meetings (a mix of one to one and small group consultations) (February-November 2010), which concentrated on addressing perceived barriers to engagement. A total of 27 stakeholder organisations took part in the consultations, including: construction companies and practitioners, advisory groups, umbrella professional organisations, consultants, policy makers and education and training bodies.

Due to the nature of the various consultations there is a need for anonymity of participants; however Table 1 provides an illustration of the representative nature of the stakeholder organisations that have taken part in our two studies in Wales:

Table 1. Illustration of the Wales participant organisations

\begin{tabular}{ll}
\hline \multicolumn{1}{c}{ Organisation name } & \multicolumn{1}{c}{ Organisation type } \\
\hline Arup & Engineering, design, planning, consultancy \\
\hline Bentley Systems & Software developer (for AEC market) \\
\hline Blaenau Gwent County Borough Council & Local Government \\
\hline bre & Consultancy/research \\
\hline Capita Symonds & Consultancy \\
\hline Carbon Trust & Advisory group \\
\hline Civil Engineering Contractors Association Ltd & Trade Association \\
\hline Constructing Excellence in Wales & Best practice organisation (built environment) \\
\hline Corus Group & Steel producer \\
\hline Cowlin Construction & Main contractor/construction company \\
\hline Davis Langdon & Consultant \\
\hline Design Commission for Wales & Public sector - design champion \\
\hline Energy Saving Trust & Non-profit energy saving advisor \\
\hline FMB & Trade Association \\
\hline Gaunt Francis & Architectural practice \\
\hline Halcrow Group Ltd & Consultant - infrastructure and planning \\
\hline Lee Wakemans & Project management, QS, H\&S \\
\hline Micaul Solar & Renewable energy systems \\
\hline Mott MacDonald & Consultancy \\
\hline Parsons Brinckerhoff & Consultancy \\
\hline Powell Dobson Architects & Architectural practice \\
\hline Rounded Development Enterprises Ltd & Social Enterprise - education in sustainable building \\
\hline &
\end{tabular}


Continued Table 1

\begin{tabular}{ll}
\hline \multicolumn{1}{c}{ Organisation name } & \multicolumn{1}{c}{ Organisation type } \\
\hline Smarta Technology & Installation - home automation and electrical \\
\hline Summit Skills & Sector skills council - education \\
\hline Utility Partnership & Utility infrastructure and energy management \\
\hline White Design & Architectural practice/sustainability consultant \\
\hline Willmott Dixon Construction Limited & Construction, housing and property \\
\hline
\end{tabular}

\section{Discussion of results from the Europe-wide and Wales consultations}

The studies indicated stakeholders' awareness and concern about the effect of ill-practices on carbon emissions and energy consumption. However, whilst many of our participants are aware that employees in organisations and on projects have moral responsibilities to deliver environmentally friendly buildings this does not systematically translate into sustainable practices and engagement as defined above, namely in terms of cognitive, affective and behavioural aspects at both a personal and organisational level. Indeed the adversarial nature of the construction industry, exacerbated by a culture of blame and tight financial margins, militates against effective actions at individual, team and to some extent organisational levels. The studies highlight possible reasons for this disparity between awareness and concern, and a pro-active level of engagement with sustainable construction. It was observed that various constraints result in limitations to engagement with sustainable construction. Consistent with the position of Lorenzoni et al. (2007) that the various barriers that function to limit cognitive, affective and behavioural elements of engagement can be interpreted either as principally personal or social, we analyse the perceived barriers in terms of the individual (section 3.1 and Table 2), organisational (section 3.2 and Table 3 ) and the wider industry levels (section 3.3 and Table 4). Tables 2, 3 and 4 present a summary achieved by review and amalgamation of the triangulated findings from the studies; they include quotes from the qualitative data and some supporting quantitative data results.

\subsection{Individual perceived barriers}

The clearest immediately identifiable perceived barrier to engagement is a lack of "actionable" knowledge about sustainable construction (Table 2), which manifests itself in various forms, including: (a) lack of knowledge pertaining to best practices; (b) the accessibility to existing relevant codified knowledge; and (c) the perception of information overload. The latter perception implies the need to note the distinction between 'knowledge' and 'information' as inferred from the comments recorded, most succinctly encapsulated by the comment regarding "drowning in a sea of information yet starving for knowledge". The epistemological dichotomy between information and knowledge is not new (Rezgui et al. 2010). A commonly held view is that data are raw numbers and facts, information is processed data, and knowledge is authenticated information (Machlup, Mansfield 1983; Vance 1997; Rezgui et al. 2010), a view commonly shared in construction circles (Rezgui et al. 2010). However, 
Table 2. Individual perceived barriers to engagement with sustainable construction

\begin{tabular}{|c|c|}
\hline $\begin{array}{l}\text { Individual perceived } \\
\text { barriers }\end{array}$ & Triangulated qualitative and quantitative examples \\
\hline $\begin{array}{l}\text { Lack of knowledge } \\
\text { about sustainable } \\
\text { construction, including } \\
\text { practices and principles; } \\
\text { availability / accessibility; } \\
\text { information overload }\end{array}$ & $\begin{array}{l}\text { "BREEAM Codes tell us what to achieve in terms of rating but not what } \\
\text { needs to be done to attain this rating." } \\
\text { "There is a need for pervasive, 'embedded' sustainable construction processes." } \\
\text { "The subject area is perceived to be enormous: people think 'where do I start?' } \\
\text { The information is there - but how to find it?" } \\
\text { "It is sometimes hard to get the basics; not so easy to find the basic stuff. } \\
\text { There is just something missing; maybe knowledge is often in people's } \\
\text { heads and you don't know who, or how to get to them." } \\
\text { "When I am faced with a } 76 \text { page report, should I read it or just skim it? } \\
\text { It's almost like learning for a degree; we need to dissect and integrate } \\
\text { the information into our systems and understand how it fits with what } \\
\text { we are doing. A library and indexing system is required; it is difficult } \\
\text { to know where to put things." } \\
\text { "We are currently drowning in a sea of information, but starving for } \\
\text { knowledge." } \\
\text { "Raw data are required; suppliers are good at providing this for specific } \\
\text { products." } \\
\text { "I need product information now; products are changing every day of the } \\
\text { week." } \\
\text { "A lot of people in power still don't know the basics." } \\
\text { In the quantitative survey the respondents were asked to indicate what } \\
\text { type(s) of information they currently need to access and use in their } \\
\text { work. The highest demand is for: Standards (79\%), and Regulatory } \\
\text { Documentation (78\%). } \\
\text { The main topics for which information is required are: Environment } \\
\text { (68\%); Energy (54\%). }\end{array}$ \\
\hline $\begin{array}{l}\text { Uncertainty and } \\
\text { scepticism } \\
\text { about the necessity for, } \\
\text { and effectiveness of } \\
\text { sustainable construction } \\
\text { practices (both industry } \\
\text { stakeholders and end- } \\
\text { users) }\end{array}$ & $\begin{array}{l}\text { "Transfer from knowledge to action: we know what to do, but not 'how?' or } \\
\text { 'why?" } \\
\text { "We know how to manipulate environmental assessment methods such } \\
\text { as BREEAM to meet current sustainability regulations. However, the } \\
\text { underpinning design interventions do not embed genuine sustainability } \\
\text { best practice". } \\
\text { "There is a need for clarity to reduce complexity." } \\
\text { "We need reliable cost information - cost/disruption/payback and reliable } \\
\text { information on renewables; and to ensure that consumers are on board } \\
\text { with the whole sustainability ethos: how much is it going to knock off my } \\
\text { energy bill/what might it do to my house/how much have I increased the } \\
\text { value of my property?" } \\
\text { "Sustainability needs to be seen as a success at the first time, otherwise 'once } \\
\text { bitten twice shy' will put people off, and push them away." }\end{array}$ \\
\hline $\begin{array}{l}\text { Distrust in information } \\
\text { sources } \\
\text { including consistency, } \\
\text { validity, authority, and } \\
\text { timeliness }\end{array}$ & $\begin{array}{l}\text { "Asidefrom that which refers to experts'specialities, sustainability information } \\
\text { is not generally transparent and can be open to interpretation. People } \\
\text { often have to talk to others for corroboration. It can take a lot of time } \\
\text { to find the bits that are useful; some companies contradict one another." } \\
\text { "Information sharing is very valuable but it is not as good as it should be } \\
\text { because of the commercial edge. We need some neutral information." }\end{array}$ \\
\hline
\end{tabular}


Continued Table 2

\begin{tabular}{|c|c|}
\hline $\begin{array}{l}\text { Individual perceived } \\
\text { barriers }\end{array}$ & Triangulated qualitative and quantitative examples \\
\hline & $\begin{array}{l}\text { "The biggest issue is trust: that people won't misuse the information that you } \\
\text { put out, and how reliable is the information you see?" } \\
\text { "Is this giving us up-to-date information? Is it easy to find? Is what we want } \\
\text { there?" }\end{array}$ \\
\hline $\begin{array}{l}\text { Reliance on technology } \\
\text { including new } \\
\text { technologies for } \\
\text { sustainability, and for } \\
\text { information retrieval }\end{array}$ & $\begin{array}{l}\text { "IT literacy varies across the supply chain." } \\
\text { "Lack of trust/faith in new technologies is a barrier to innovation." } \\
\text { From the quantitative survey web portals are the main channel to } \\
\text { access Standards ( } 82 \%) \text {, and Regulatory (87\%) documentation. There is } \\
\text { considerable dissatisfaction with this current practice: Standards } 40 \% \text {, } \\
\text { Regulatory Documentation } 44 \% \text {. }\end{array}$ \\
\hline $\begin{array}{l}\text { Resistance to lifestyle } \\
\text { change }\end{array}$ & $\begin{array}{l}\text { "There is a need to change people's behaviour - promoting/implementing } \\
\text { sustainable lifestyles." }\end{array}$ \\
\hline $\begin{array}{l}\text { Perceived threats } \\
\text { include changes in } \\
\text { living standards, } \\
\text { inconvenience, cost }\end{array}$ & $\begin{array}{l}\text { "Various barriers may be identified, including: lack of understanding } \\
\text { the consequences of our actions; making changes everyday; lack of } \\
\text { consistency of information; and that consumers don't want to act alone. } \\
\text { "Practitioners need to ask fundamental questions even for the client, for } \\
\text { example 'how will you live there?' Social factors have to be understood. } \\
\text { Sustainable building is: social, environmental, and financial." } \\
\text { "Behaviour change also includes detailed payback to the householders." }\end{array}$ \\
\hline
\end{tabular}

it can be argued that the presumption of hierarchy from data to information to knowledge with each varying along some dimension such as context, usefulness or interpretability can be open to interpretation (Rezgui, Miles 2009). Indeed, it emerged from the workshops that there should be a widely disseminated selection of the 'top ten' most important documents regarding sustainable construction. This suggests that large quantities of information are available, but they are widely dispersed and non-integrated, which introduces further complexity and barriers to innovation (Barrett, Sexton 2006).

This lack of, or abundance of ill-structured, knowledge may be a factor in creating uncertainty and scepticism about the necessity and effectiveness of sustainable construction. Practitioners indicate a need for clarity both for themselves and also to ensure that consumers buy into the need for sustainability activities during the operational stage of a building or facility. It is implicit in the statements regarding payback to consumers that in the case of some individuals a lack in transference of knowledge into action - being able to understand and explain 'how' and 'why' sustainable practices need to be adopted - constitutes a barrier to engagement. This is in line with observations made by the Low Carbon Construction Innovation and Growth Team (IGT) including: "Where people are inclined to act through a sense of personal or corporate social responsibility, then either they will have done so, or they are prevented from doing so by a barrier to action. These will include the lack of available capital, or a reluctance to invest in improving the energy efficiency of a building when it may be sold long before payback" (HM Government 2010). Furthermore, the IGT note that cost acts as a disincentive to retrofit as evidenced by the most frequently asked question during their work being: 'How are we going to pay for all of this?' (HM Government 2010). Additionally, 
distrust in information sources exacerbates the disengagement because individuals feel that contradictions exist between information sources, and a lack of transparency leads to information being open to interpretation, as explicitly stated in the comment "...sustainability information is not generally transparent and can be open to interpretation... some companies contradict one another." The respondents indicate that commercial considerations bias the information available to them and there is a desire for reliable neutrality.

The studies indicate that web portals are a primary channel for accessing information by stakeholders, however there is widespread dissatisfaction with this method of retrieval. The need for dependable up-to-date information ensures that electronic media are heavily relied upon, yet wide variation in technological literacy remains a barrier to engagement in the industry. Conversely, this reliance on technology for information retrieval remains a barrier to engagement as it is closely tied to distrust in the sources, as shown by the comment "Is this [source] giving us up-to-date information? Is it easy to find? Is what we want there?" Our studies also indicate reliance on technology to be a barrier with regard to the plethora of energy tools available to aid in sustainable design (e.g. calculation tools, simulation tools, etc.) requiring specialist and expensive expertise; energy tools need to be user friendly, integrated with common design tools, and require minimum learning/training prior to use.

Resistance to changes in lifestyle emerged as a significant perceived barrier to engagement in sustainable construction, explicitly stated in such comments as: "Practitioners need to ask fundamental questions even for the client, for example 'how will you live there?' Social factors have to be understood" and "Various barriers may be identified, including: lack of understanding the consequences of our action." This is reflected in the literature indicating that whilst recent energy price increases have made people more aware of their behaviour, resulting in increased interest in, and installation of, energy efficiency measures, barriers that prevent householders from going further include: disbelief in the putative savings, savings being too small to overcome the disruption involved, concerns over the health and comfort effects of air-tightness and over-heating, and the fact that some householders just aren't interested (HM Government 2010). From our studies the practitioners feel that the end users' lack of understanding the consequences of their actions requires contextualisation of new concepts because terminology is 'key', and also that they must be able to identify who is trusted and who the decision makers are. These findings are also in line with the difficulties people have with visualising the consequences of their activities in terms of future climate change and that they tend to pay attention to immediate and personally relevant issues (Lorenzoni et al. 2007; Moser, Dilling 2004; Wilson 2002).

\subsection{Organisational perceived barriers}

The first perceived barrier in this category (Table 3) is the lack of a supportive organisational culture reflected in positive initiatives that enable sustainability information and knowledge nurturing. Participants emphasize the negative effect to engagement induced by the diversity of information they are faced with and the resulting information overload. It is interesting in this respect to note the "law of requisite variety" which states that only variety can destroy 
Table 3. Organisational perceived barriers to engagement with sustainable construction

\begin{tabular}{|c|c|}
\hline $\begin{array}{l}\text { Organisational perceived } \\
\text { barriers }\end{array}$ & Triangulated qualitative and quantitative examples \\
\hline $\begin{array}{l}\text { Lack of enabling initiatives } \\
\text { Information and knowledge } \\
\text { sources are fragmented, } \\
\text { diverse, unstructured, non- } \\
\text { integrated }\end{array}$ & $\begin{array}{l}\text { "Better collaboration [mechanisms] are required to source new materials } \\
\text { and supply channels for them and to smooth processes throughout } \\
\text { the supply chain." } \\
\text { "Poor networking inhibits progress through a lack of communication." } \\
\text { "The first port of call is often to post questions on a forum; sometimes } \\
\text { you get answers that are more useful to someone else, but it provides } \\
\text { leads to follow up." } \\
\text { "If internet searching fails the next step is to ask 'whom do I know who } \\
\text { might know?" } \\
\text { "Searching on particular websites is often rather unsatisfying; you } \\
\text { need to know exactly where to look. We don't have time to keep } \\
\text { up with other people's websites and [current practice] needs to be } \\
\text { streamlined: we need to find and agree on the most important } \\
\text { and most helpful pieces of information. There is the danger of } \\
\text { information overload - there is loads of good information out there } \\
\text { but no way to find and read it all. So many 200 page reports - } \\
\text { where is the piece that is interesting/relevant?" } \\
\text { "There is a need for videos on leaning up operations and to disseminate } \\
\text { best practice. Plus, practical guides on-site - this is how to do xyz'; } \\
\text { savings in reducing snagging." } \\
\text { Accessibility of information is the most important barrier regarding } \\
\text { all of the information types in the quantitative survey: Standards } 55 \% \text {, } \\
\text { Regulatory Documentation } 59 \%\end{array}$ \\
\hline
\end{tabular}

Lack of training Including understanding the skills need; raising the demand for skills; understanding how to up-skill the workforce
"A Builders qualification is needed and then a platform for more knowledge, suppliers, etc. Also this should be in 2 parts: standard information and flexible where others can put in their knowledge."

"We share knowledge between ourselves and key designers, but we are only very slowly managing to educate the clients and contractors."

"There is a preponderance of 'general' and low-skilled workers, therefore a need for fairly simple regular refresher courses."

"There are huge gaps in understanding - procurement issues especially particularly in the public sector; individual clients don't know the question."
Work overload and priority to expedite current tasks and activities Including within tight financial margins

"Procurement is an issue - alterations to current procurement processes."

"We should be allowing designers freedom to increase potential for innovation; we are seeing lots of good stuff, but the economic climate is not helping."

"The [sustainability] targets are not necessarily the top concern in CE; the financial/economic climate is more of a concern."

"Sustainable procurement and whole-life costing are now being addressed, but this is a bloody nightmare..."

"The concern is putting [sustainability] into practice; how deeply do people understand the legislation and put it into practice?"

Lack of time for reflective actions and capitalizing on lessons learnt
"If someone makes a mistake, how do we stop the others making the same mistake?" 
Continued Table 3

$\begin{gathered}\text { Organisational perceived } \\ \text { barriers }\end{gathered}$
"We need to understand best practice - but were also developing it:
what we need to do is to instil into everyone the value of it. If it
is instilled in the ethos of how you approach the job, then it is the
natural way. The challenge is to ensure that you are trying to solve
the right problem!"
"We don't have time to share documents around - what do we get out
of it?"
"There may be some reluctance to share from other companies because
of the feeling that if you tell everyone what you know it will affect
competition."
"There is good sharing of information between design teams, but
inter-architects there is little because we have to strike commercial
interests with cooperation."
including commercial
imperative, costs, trust

variety (Ashby 1956). In fact, while carrying out their tasks individuals must effectively manage the complexity they face (Kidd 2013). This complexity involves the internal and external environment of the organisation. It is important for the internal diversity of an organisation to match the variety of the external diversity in order to cope with changes in this environment (Chilton, Bloodgood 2010). More importantly, organisations need to find a balance between factors that attenuate environmental complexity and those that amplify managerial complexity. However, modern organisations involve too much amplification, and too little attenuation (Kidd 2013). A parallel can easily be drawn with web-based information portals. These tend to focus on informational needs of individuals, while the environment in which such information is provided is often overlooked. Greater emphasis should be given to the processes that underpin knowledge activities, as opposed to the information and knowledge itself. This situation is exacerbated in a social context by limited collaboration mechanisms across the supply chain and throughout the construction lifecycle. Many of our participants maintain that poor networking infrastructures lead to unacceptable demands on their already tight time constraints, with dissatisfaction leading them to rely on whom they know being available to answer questions via traditional methods. Such activities are also dissatisfying as the people on whom they rely are also bound by the same lack of enabling initiatives and cannot be sure that they know exactly where to look for the required knowledge.

Another constraint explicitly identified by a wide cross section of participants was an immediate requirement for training throughout the industry, which is in line with the literature (e.g. Cardoso Teixeira et al. 2006; Vakola, Wilson 2004). This barrier is perceived to be 
extensive as it includes not only the 'general' and low-skilled workforce that is a perennial characteristic of the industry, but also the huge gaps in understanding in the public sector, and the need to educate clients. It was noted in one workshop, for example, that a worker may be supplying the most highly energy efficiency rated window but unless he knows how to fit it properly it will be rendered energy inefficient. This implies not only a need for up-skilling but also a lack in understanding the sustainability implications of common work practices. There is also a financial constraint embedded in this barrier - as one participant noted: "we have to consider finance - the necessary changes may imply increased expense." This consideration is also explicitly tied in with the perceived barrier of work overload and priority to expedite current tasks and activities. The industry remains constricted by tight financial margins, the result being that economic concerns are taking precedence over sustainability targets.

A clear requirement that emerged from our studies relates to best practice, which is perceived as a double-edged sword as it needs to be understood, but is also the responsibility of the organisations at large to develop and produce. A lack of time for reflective actions and capitalizing on lessons learnt is perceived as a barrier in this respect, and one that is closely tied to the lack of enabling initiatives and implicitly to cost constraints. Through positive reflection individuals are able to 'surface and criticise the tacit understandings that have grown up around the repetitive experiences of a specialised practice or task, and can make new sense of the situations of uncertainty or uniqueness which they may allow themselves to experience' (Schön 1983). Sensemaking emerges as an important factor. This involves making sense of the unknown by introducing structure and order, and exploring how individuals construct realities, and the effect this has on their environment (Weick 1996). In fact, the organisation may be seen as a system of perception, engaged in continuous sensemaking. Individuals create and share knowledge within their environment, i.e. the organisation or project at hand, and by doing so construct and express their own identity, and as a result have a positive effect on their environment. Nurturing know-how is thus perceived as a social process continuously influenced by individuals, their knowledge and the ways this is shared and used in their environment, i.e. team or organisation. Making sense of situations influences positive sustainability actions and triggers a sustainability-informed decision-making processes (Rezgui, Miles 2011). It is also symptomatic of the final perceived barrier in this category - lack of information/knowledge sharing. One participant noted quite clearly that "information sharing has almost stopped because of competitive edge/advantage. It is environment driven.” Information/knowledge sharing is a cornerstone to the promotion of construction stakeholders' engagement with sustainability, which is evidenced directly in terms of cognitive, affective and behavioural aspects. The participants on the whole recognise a need and great benefit in sharing, yet whilst it occurs within teams and organisations there is a reluctance to share 'outside' due to commercial interests, most notable in the comment "Why should I share the information I have spent years developing for my competitors to take advantage?” Furthermore, in terms of best practice and lessons learnt the shared information is generally viewed as being mere showcasing of key results to demonstrate achievements according to the codes of practice now put in place legislatively, rather than the necessary knowledge of how such things were achieved and the common failures that were overcome. 


\subsection{Wider industry perceived barriers}

The perceived barriers from the wider industry perspective generally put responsibility back on the government. Firstly there is perceived lack of government action to initiate and promote energy positive behavioural change. The implicit assumption may be construed as being that the government were responsible for the original targets and aspirations for reducing carbon emissions, energy consumption, waste, etc, but relied on an initially largely un-knowledgeable industry to achieve them. (Indeed there was even confusion with regard to the nature of the 'targets' with some participants noting that latterly these became 'aspirations'). Our studies indicate that participants feel there should be far greater support from the government to aid the industry as a whole with regard to perceived barriers such as resistance to lifestyle change, and that a common, shared perception is still lacking. This tendency to place responsibility

Table 4. Wider industry perceived barriers to engagement with sustainable construction

$\begin{gathered}\text { Wider Industry perceived } \\ \text { barriers }\end{gathered}$
$\begin{aligned} & \text { Triangulated qualitative and quantitative examples } \\ & \text { to initiate and promote } \\ & \text { energy positive } \\ & \text { behavioural change }\end{aligned} \quad$ of generinted thinking - there is a lack of common, shared perception; a lack
"We know the direction that we need to go in but there is a whole industry
that has to help us make this change."
"We have made progress but we are not on track due to a mismatch between
'minister versus local delivery', and it is difficult to make changes in
legacy buildings but we can do it with new build."
"There is a need for action on increasing public awareness of the benefits
of good design."
"It's all very well for the [Welsh Government] to advocate and pontificate
about sustainability, but it needs to manage it correctly."
"Uploading information from Housing Associations: tends to be community
driven. The agents dictate the extent of sustainable practice because
their priority is to let."
"Is there a possibility to learn from other sectors? Is there a model that can
be applied?"
"What's going on in the [Welsh Government] - the political thinking?"
"Why do we have to pay for sustainability information? BRE are playing a
double act, i.e. legislator and competitor".
"Whilst there are some good things going on in Wales, the industry strives
to meet minimum standards and no more."
"The industry generally wants to reduce emissions but end users need to
be on board"
"Building Regs are not on board; whilst there are initiatives to create change
there is still the question whether or not there is training for planners
on Low/Zero Carbon?"
"How do the LC targets link in with waste, energy; what is mandatory?
"There is a need to address knowledge (education even) of Councillors/
elected members who make the decisions but don't understand
sustainability. Also local authority planners/other professionals who
are driven by compliance and don't have incentive to look at wider
value/risk perspective (but need to)."


with government may in some cases indicate denial mechanisms as described in the climate change literature (Lorenzoni et al. 2007; Stoll-Kleeman et al. 2001). The literature discussing public engagement with climate change, and in particular mechanisms for understanding, indicates an increased awareness of the concept of 'carbon footprints', an increase in the use of carbon calculators, and information about tools such as smart meters, etc. However, information provision alone is insufficient to address competing values or the wider, structural barriers to low-carbon lifestyles, and may leave people feeling disempowered, disinterested or cynical about attempts by government to 'educate' the public by locating responsibility for climate action with individuals (Whitmarsh et al. 2011; Hargreaves 2010). Examples of denial mechanisms include denying personal contribution to climate change and personal responsibility, pointing to government inaction, claiming ignorance, being too busy to change one's behaviour, and focusing on other issues that are perceived to be of greater importance (Lorenzoni et al. 2007).

Secondly and closely related to this first barrier, is the perception that the government's primary focus is on regulation without recognising the depth of the increased challenges faced by an industry that is suffering from poor stakeholder awareness and education. Some participants imply that the latest thinking in the corridors of government is not clearly stated, for example one participant noted: "we need to be updated every 6 months. What is the latest on national standards, landlords' expectations on building codes, etc.? What are expectations in say 2, 3 years time?" There is perceived to be a mismatch in understanding between government members and practitioners, which results in a lack of engagement because the industry has to expend too much resource on simply meeting the required standards.

\section{Discussion}

The observations above indicate that some overlaps exist across the categorised areas. These concurrences appear to intensify constraints to engagement. For example, the perceived need to transfer knowledge into action, the need to know 'how' and 'why', is cited as a clear lack of widely available knowledge and a barrier due to uncertainty, whilst competitive advantage continues to deter people from sharing their information. The individual barriers include: lack of knowledge; uncertainty and scepticism; distrust in information sources; reliance on technology; and resistance to lifestyle change. Organisational barriers involve: lack of enabling initiatives; lack of training; work overload and priority to expedite current tasks and activities; lack of time for reflective actions and capitalizing on lessons learnt; and lack of information/knowledge sharing. The wider industry barriers are subdivided into: lack of government action; and government focus on regulation.

Overall the perceived barriers to engagement suggest a comprehensive requirement for behaviour change as a complex combination of contextual forces, personal capabilities and habits, and attitudinal factors are influencing current behaviour (Stern 2000). At this level individuals' behaviour may be viewed to be aligned with elements of the theory of planned behaviour (Ajzen 1991) which emphasizes that human behaviours are governed not only by personal attitudes, but also by social pressures and a sense of control, and its precursor - the theory of reasoned action - in which behaviour is determined by the intentions of indi- 
viduals (Ajzen, Sheikh 2013). However, as our definition of the term "engagement" in this paper extends cognitive, affective and behavioural aspects at an individual level to embrace wider values embedded within the organisational culture, we feel that the ipsative theory of behaviour - which identifies internal and external conditions as potential constraints to pro-environmental action (Tanner 1999) - is more illustrative. The ipsative theory of behaviour holds that both internal and external conditions may constrain behaviour (Frey 1988), and in contrast to traditional psychological research, it points out the why of nonaction rather than focusing on the reasons for action (Tanner 1999). Three presuppositions for human behaviour are assumed: objective constraints, ipsative constraints, and subjective constraints. Objective constraints influence the performing of an act, and may comprise structural factors which include time limitations, cost, legal and political institutions, the current state of scientific knowledge, available technology, state of infrastructure, and available social interaction and information network (Tanner 1999), all of which are evident from our studies. Ipsative constraints prevent activation of behavioural alternatives - this may be illustrated, for example, in the decision whether or not to share information to enable engagement, as an individual's action is not constrained by the objective condition but by the fact that the particular alternative did not occur to him or her (Tanner 1999). Subjective constraints prevent the preference for behavioural alternatives. As construction stakeholders operate within the organisational compass behaviour is to some extent dictated by the organisational culture, therefore subjective constrains may directly affect engagement in sustainable construction as they prevent a desire to act and are responsible for the exclusion of particular behaviour alternatives in the ipsative set (Tanner 1999).

The results from our consultations and the exploration of the key perceived barriers confirmed that sustainability knowledge in construction is fragmented, diverse, embedded in various documents, and developed in a non-concerted and integrated way across stakeholders, localities, regions, and countries. It also identified and established the need to create circles of impacts that bind building professionals, energy administrations, and citizens in a shared sustainability experience to address a number of issues, including:

- Lack of sharing, exploitation, and reuse of isolated sustainable practices and principles acquired through practice across the industry.

- Lack of education and awareness across key construction stakeholders and building end-users.

- Lack of easy access to structured sustainability information and knowledge.

- Unclear links between sustainability principles and current construction regulations and standards. (In fact, there is no explicit statutory requirement that the Building Regulations should cover sustainability, even though many of the approved documents already do so. This is a substantial statutory barrier to progress on the sustainability of buildings).

- Uncertainty about the cost of sustainable solutions/technologies.

Throughout the studies we became increasingly aware that "Islands of Information" exist across the field of sustainable construction. Different actors have built various repositories, organised events, etc., in an effort to fully understand the changing construction landscape, 
but with little or no coordination or awareness of what one another is doing. With this in mind, in the Wales LZC Hub workshop the notion of creating a "Map of Everything" emerged, which was rated as the most highly weighted issue of immediate concern to the participants. The notion of a "Map of Everything" referred to a need to map out the structural and social elements involved in sustainability including the key organisations and people, information and training events, key publications, online forums, etc. We recognised from the results that a socio-technical 'knowledge solution' that factors in people attitudes and behaviours, within the wider context of their organisation and industry communities, alongside technical considerations may act as a welcome bridge between these "Islands of Information", and thereby address the issues outlined above.

Alavi and Leidner (2001) note that knowledge may be viewed from five different perspectives:

- state of mind perspective, emphasizing knowing and understanding through experience and study (Schubert et al. 1998);

- object perspective, defining knowledge as a thing to be stored and manipulated (Rezgui 2007, 1996; McQueen 1998; Zack et al. 2009);

- process perspective, focusing on knowing and acting (Zack et al. 2009);

- condition perspective, emphasizing access to knowledge (McQueen 1998); and

- capability perspective, viewing knowledge as a capability.

These different views of knowledge lead to different perspectives of Knowledge Management (KM) (Carlsson et al. 1996):

- IT perspective, focusing on the use of various technologies to acquire or store knowledge resources (Borghoff, Pareschi 1998). As knowledge is viewed as an object, KM should focus on ensuring that explicit knowledge, available in the form of knowledge items, is widely accessible across an organisation.

- Socialization perspective, focusing on understanding the organisational nature of KM (Gold, Malhotra 2001; Rezgui et al. 2010). KM should focus on supporting the processes of sharing, creating, and disseminating knowledge.

- Information system (IS) perspective, focusing on both IT and organizational capability and emphasizing the use of KMS (Tiwana 2001; Schultze, Leidner 2002; Rezgui 2007). The right KM strategy should be put in place to develop and nurture core organisational competencies, and create intellectual capital.

Our concept of socio-technical system relates to the third (Information System) perspective as reported in related studies in the construction industry (Rezgui 2007; Rezgui, Miles 2011). As such, this could be delivered as a "one-stop-shop" web-based platform, a concept that was further explored within the third study. It emerged that such a solution may address the perceived barriers to engagement with sustainable construction, particularly for the many SME organisations characteristic of the industry, but may also aid large organisations that already rely on their own intranets; as the director of one multinational construction firm noted:

"Yes, there is absolutely a need for a central platform. For smaller organisations getting answers is still a fog - there is a need for a source." 


\section{Conclusions}

The paper suggests that sustainable construction goals can only be achieved if shared and value-added relevant resources of knowledge and expertise inform design, construction and operation activities across the supply chain. Two research questions are outlined that formed the focus of the research. In terms of construction stakeholders' sustainability information needs and government provision deficiencies (RQ1), limited sustainability best practice/ regulation awareness and information provision deficiencies emerged as key themes from the Europe-wide and Wales studies and provided the ground to address the second research question (RQ2). As to construction stakeholders' engagement barriers with governmental carbon and energy reduction targets (RQ2), findings from these studies indicate an overall awareness and concern about environmental issues and the need to address these through sustainable construction activities. However, whilst stakeholders are aware that ill-practices in the construction industry can have major drawbacks on meeting governmental targets on carbon and energy reduction, and that employees in organisations and on projects have moral responsibilities to deliver environmentally friendly buildings, this does not systematically translate into sustainable practices and engagement as defined in terms of cognitive, affective and behavioural aspects at a personal, organisational, and wider industry level. Finally, the results from the studies indicate that a shared sustainability knowledge experience, in the form of a web-based "one-stop-shop" platform may promote more systematic engagement with a view to meeting governmental energy and carbon reduction targets and therefore be beneficial in addressing the perceived barriers to engagement. The authors are now pursuing their efforts with the delivery of a full, exploitable "one-stop-shop" platform as a socio-technical solution to the perceived barriers from these studies.

\section{Acknowledgements}

The European-wide study was funded by the European Commission under the FP7 programme. The Wales studies were funded by the Welsh Government under the Academic Expertise for Business (A4B) programme. The authors would also like to acknowledge the many industrial/stakeholder organisations and individuals who have kindly taken part in the various studies.

\section{References}

Ajzen, I. 1991. The theory of planned behavior, Organizational Behavior and Human Decision Processes 50: 179-211. http://dx.doi.org/10.1016/0749-5978(91)90020-T

Ajzen, I.; Sheikh, S. 2013. Action versus inaction: anticipated affect in the theory of planned behaviour, Journal of Applied Social Psychology 43: 155-162. http://dx.doi.org/10.1111/j.1559-1816.2012.00989.x

Chilton, M. A.; Bloodgood, J. M. 2010. Adaption-innovation theory and knowledge use in organizations, Management Decision 48(8): 1159-1180. http://dx.doi.org/10.1108/00251741011076726

Barrett, P. S.; Sexton, M. G. 2006. Innovation in small, project based construction firms, British Journal of Management 17: 331-346. http://dx.doi.org/10.1111/j.1467-8551.2005.00461.x

Becerra-Fernandez, I.; Sabherwal, R. 2001. Organisational knowledge management: a contingency perspective, Journal of Management Information Systems 18(1): 23-55. 
BERR 2007. Digest of UK energy statistics [online], Department for Business Enterprise and Regulatory Reform, London [cited 24 March 2012]. Available from Internet:

http://stats.berr.gov.uk/energystats/dukes07_c6.pdf.

Blake, D. E. 2001. Contextual effects on environmental attitudes and behaviour, Environment and Behaviour 33: 708-725. http://dx.doi.org/10.1177/00139160121973205

Borghoff, U. M.; Pareschi, R. 1998. Information technology for knowledge management. Berlin: Springer Verlag. http://dx.doi.org/10.1007/978-3-662-03723-2

BSRIA 2009. Zero carbon targets on the construction industry [online], [cited 30 July 2012]. Available from Internet: http://www.bsria.co.uk/news/clean-home/

Burgess, J.; Nye, M. 2008. Rematerialising energy use through transparent monitoring systems, Energy Policy 36: 4454-4459. http://dx.doi.org/10.1016/j.enpol.2008.09.039

Clarke, J. A.; Johnstone, C. M.; Kelly, N. J.; Strachan, P. A.; Tuohy, P. 2008. The role of built environment energy efficiency in a sustainable UK energy economy, Energy Policy 36: 4605-4609. http://dx.doi.org/10.1016/j.enpol.2008.09.004

Cardoso Teixeira, J. M.; Minasowicz, A.; Zavadskas, E. K.; Ustinovichius, L.; Migilinskas, D.; Pellicer Armiñana, E.; Nowak, P. O.; Grabiec, M. 2006. Training needs in construction project management: a survey of 4 countries of the EU, Journal of Civil Engineering and Management 12(3): 237-245.

DEFRA 2002. Survey of public attitudes to quality of life and to the environment: 2001. Department for Environment, Food and Rural Affairs, London.

Egemen, M.; Mohamed, A. N. 2005. Different approaches of clients and consultants to contractors' qualification and selection, Journal of Civil Engineering and Management 11(4): 267-276. http://dx.doi.org/10.1080/13923730.2005.9636357

European Commission 2005. Challenging and changing Europe's built environment: a vision for a sustainable and competitive construction sector by 2030. European Construction Technology Platform.

Gold, A. H.; Malhotra, A. 2001. Knowledge management: an organisational capabilities perspective, Journal of Management Information Systems 18(1): 185-214.

Hargreaves, T. 2010. The visible energy trial: insights from qualitative interviews [online], Tyndall Centre Working Paper 141, Tyndall Centre for Climate Change Research, Norwich [cited 30 July 2011]. Available from Internet: http://www.tyndall.ac.uk/publications/working-paper/2010/visible-energy-trial-insights-qualitative-nterviews

HM Government 2010. Low carbon construction innovation and growth team: final report [online], HM Government [cited 30 July 2011]. Available from Internet: http://www.bis.gov.uk/assets/biscore/ business-sectors/docs/1/10-1266-low-carbon-construction-igt-final-report.pdf

IPCC 2001. Climate change 2001: synthesis report. Summary for Policymakers. Intergovernmental Panel on Climate Change, Geneva.

IPCC 2007. The physical science basis. Summary for policymakers. Contribution of Working Group I to the Fourth Assessment Report of the Intergovernmental Panel on Climate Change. Geneva.

Kidd, J. 2013. The 'law of requisite variety' may assist climate change negotiations: a review of the Kyoto and Durban meetings, Knowledge Management Research \& Practice Advance online publication, 14 January 2013. http://dx.doi.org/10.1057/kmrp.2012.56

Klöcknera, C. A.; Blöbaumb, A. 2010. A comprehensive action determination model: toward a broader understanding of ecological behaviour using the example of travel mode choice, Journal of Environmental Psychology 30(4): 574-586. http://dx.doi.org/10.1016/j.jenvp.2010.03.001

Kollmuss, A.; Agyeman, J. 2002. Mind the gap: why do people act environmentally and what are the barriers to pro-environmental behavior, Environmental Education Research 8: 239-260.

http://dx.doi.org/10.1080/13504620220145401 
Lichtenstein, S.; Slovic, P. 2006. The construction of preference. New York: Cambridge University Press. http://dx.doi.org/10.1017/CBO9780511618031

Lill, I. 2009. Multiskilling in construction - a strategy for stable employment, Technological and Economic Development of Economy 15(4): 540-560. http://dx.doi.org/10.3846/1392-8619.2009.15.540-560

Lorenzoni, I.; Nicholson-Cole, S.; Whitmarsh, L. 2007. Barriers perceived to engaging with climate change among the UK public and their policy implications, Global Environmental Change 17: 445-459. http://dx.doi.org/10.1016/j.gloenvcha.2007.01.004

Machlup, F.; Mansfield, U. 1983. The study of information: interdisciplinary messages. New York: Wiley \& Sons.

Martinaitis, V. 2006. Editorial: energy for buildings, Journal of Civil Engineering and Management 12(1): 1-2.

Mathur, V. N.; Price, A. D. F.; Austin, S. 2008. Conceptualizing stakeholder engagement in the context of sustainability and its assessment, Construction Management and Economics 26(6): 601-609. http://dx.doi.org/10.1080/01446190802061233

McQueen, R. 1998. Four views of knowledge and knowledge management, in Hoadley, E.; Benbasat, I. (Eds.). Proceedings of the Fourth Americas Conference on Information Systems, University of New South Wales, Sydney, 609-611.

Morgan, M. G.; Fischhoff, B.; Bostrom, A.; Atman, C. J. 2002. Risk communication: a mental models approach. CUP.

Moser, S. C.; Dilling, L.; 2004. Making climate hot: communicating the urgency and challenge of global climate change, Environment 46: 32-46. http://dx.doi.org/10.1080/00139150409605820

MPA, 2011. Operation and embodied CO2 [online], MPA - The Concrete Centre [cited 30 July 2011]. Available from Internet: http://www.concretecentre.com/technical_information/performance_and_ benefits/thermal_mass/operation_and_embodied_co2.aspx

Norton, A.; Leaman, J. 2004. The day after tomorrow: public opinion on climate change. MORI Social Research Institute, London.

Nye, M.; Whitmarsh, L.; Foxon, T. 2010. Sociopsychological perspectives on the active roles of domestic actors in transition to a lower carbon electricity economy, Environment and Planning 42: 697-714. http://dx.doi.org/10.1068/a4245

Rezgui, Y.; Miles, J. C. 2009. Exploring the potential of SME alliances in the construction sector, Construction Engineering and Management 136(5): 558-567. http://dx.doi.org/10.1061/(ASCE)CO.1943-7862.0000150

Rezgui, Y.; Miles, J. C. 2011. Harvesting and managing knowledge in construction: from theoretical foundations to business applications. London: Taylor \& Francis, Spon Press.

Rezgui, Y.; Wilson, I.; Li, H. 2010. Promoting sustainability awareness through energy engaged virtual communities of construction stakeholders, in Proceedings of the 11th IFIP Working Conference on Virtual Enterprises, 11-13 October 2010, Saint-Etienne, France.

Rezgui, Y. 2007. Knowledge systems and value creation: an action research investigation, Industrial Management \& Data Systems 107(2): 166-182. http://dx.doi.org/10.1108/02635570710723796

Rezgui, Y.; Marks, A. 2008. Information security awareness in higher education: an exploratory study, Computers and Security 27 (7-8): 241-253. http://dx.doi.org/10.1016/j.cose.2008.07.008

Rezgui, Y.; Hopfe, C.; Vorakulpipat, C. 2010. Generations of knowledge management in the architecture, engineering and construction industry: an evolutionary perspective, Advanced Engineering Informatics 24(2): 219-228. http://dx.doi.org/10.1016/j.aei.2009.12.001

Rip, A.; Kemp, R. 1998. Technological change, in Rayner, S.; Malone, E. (Eds.). Human choices and climate change. Battelle, Columbus, Ohio, 2: 327-392. 
Schellnhuber, H. J.; Cramer, W.; Nakicenovic, N.; Wigley, T.; Yohe, G. 2006. Avoiding dangerous climate change. Cambridge: Cambridge University Press.

Schön, D. 1983. The reflective practitioner: how professionals think in action. New York: Basic Books.

Schubert, P.; Lincke, D.; Schmid, B. 1998. A global knowledge medium as a virtual community: the net academy concept, in Hoadley, E.; Benbasat, I. (Eds.). Proceedings of the Fourth Americas Conference on Information Systems, Baltimore, 618-620.

Schultze, U.; Leidner, D. E. 2002. Knowledge management in IS research, MIS Quarterly 26(3): 213-242. http://dx.doi.org/10.2307/4132331

Smith, A.; Stirling, A.; Berkhout, F. 2005. The governance of socio-technical transitions, Research Policy 34: 1491-1510. http://dx.doi.org/10.1016/j.respol.2005.07.005

Spence, A.; Poortinga, W.; Butler, C.; Pidgeon, N. F. 2011. Perceptions of climate change and willingness to save energy related to flood experience, Nature Climate Change 1: 46-49. http://dx.doi.org/10.1038/nclimate1059

Steg, L.; Vlek, C.; Slotegraaf, G. 2001. Instrumental-reasoned and symbolic-affective motives for using a motor car, Transportation Research Part F: Traffic Psychology and Behaviour 4: 151-169. http://dx.doi.org/10.1016/S1369-8478(01)00020-1

Stern, P. 2000. Toward a coherent theory of environmentally significant behaviour, Journal of Social Issues 56: 407-424. http://dx.doi.org/10.1111/0022-4537.00175

Stoll-Kleemann, S.; O’Riordan, T.; Jaeger, C. C. 2001. The psychology of denial concerning climate mitigation measures: evidence from Swiss focus groups, Global Environmental Change 11: 107-117. http://dx.doi.org/10.1016/S0959-3780(00)00061-3

Tanner, C. 1999. Constraints on environmental behaviour, Journal of Environmental Psychology 19: 145-157. http://dx.doi.org/10.1006/jevp.1999.0121

Tiwana, A. 2001. The knowledge management toolkit: practical techniques for building knowledge management systems. Englewood Cliffs, NJ: Prentice-Hall.

Vakola, M.; Wilson, I. E. 2004. The challenge of virtual organisation: critical success factors in dealing with constant change, Team Performance Management 10(5-6):112-120. http://dx.doi.org/10.1108/13527590410556836

Vance, D. 1997. Information, knowledge and wisdom: the epistemic hierarchy and computer-based information systems, in AMCIS 1997 Proceedings, August 1997, Indianapolis.

van Vliet, B.; Chappells, H.; Shove, E. 2005. Infrastructures of consumption. London: Earthscan.

WAG 2009. Sustainable buildings in Wales: bream 'Excellent', code for sustainable homes and the zero carbon aspiration [online], [cited 30 July 2011]. Available from Internet: http://www.claw.gov.uk/fileadmin/ claw/Sustainability/Sustainability_Guide_WAG_-_Jan_09.pdf

Weick, K. 1996. Prepare your organisation to fight fires, Harvard Business Review (May-June): 143-148.

Whitmarsh, L.; O’Neill, S.; Seyfang, G.; Lorenzoni, I. 2009. Carbon capability: what does it mean, how prevalent is it, and how can we promote it? [Online], Tyndall Working Paper, No. 132 [cited 30 July 2011]. Available from Internet: http://www.tyndall.ac.uk/Tyndall-Publications/Working-Paper/2009/ Carbon-Capability-what-does-it-mean-how-prevalent-it-and-how

Whitmarsh, L.; Seyfang, G.; O’Neill, S. 2011. Public engagement with carbon and climate change: to what extent is the public 'carbon capable'?, Global Environmental Change 21: 56-65.

http://dx.doi.org/10.1016/j.gloenvcha.2010.07.011

Wilson, E. O. 2002. The future of life. London: Little Brown.

Zack, M.; McKeen, J.; Singh, S. 2009. Knowledge management and organizational performance: an exploratory analysis, Journal of Knowledge Management 13(6): 392-409.

http://dx.doi.org/10.1108/13673270910997088 
Ian E. WILSON is a Senior Researcher who was awarded his $\mathrm{PhD}$ in informatics in 2003. He has been involved in several successfully completed EC (FP5 and FP6) projects, and has published in journals, conference proceedings in the UK and Europe, and one book chapter. His main areas of research interest have been in virtual enterprise and organisation, BPR, change management and the human and organisational aspects of technology transfer applied to the construction sector.

Yacine REZGUI is a Professor in engineering informatics. He has a $\mathrm{PhD}$ in computer science in the area of document engineering. He directs the BRE (Building Research Establishment) Institute of Sustainable Engineering at Cardiff University. Over the last 15 years he has developed solutions to support collaboration and cooperation needs of global virtual teams, and promote effective knowledge management in organizations and on projects. He has published over 100 peer-reviewed articles, and has completed over 17 research and development projects, funded by national and European research councils, in collaboration with leading organizations across Europe. He conducts research in areas related to software engineering (including service-oriented architectures), information and knowledge management (centred around the use of Ontology), and virtual enterprises. 